\title{
Neurofibromatosis type 6
}

INSERM

\section{Source}

INSERM. (1999). Orphanet: an online rare disease and orphan drug data base.

Neurofibromatosis type 6. ORPHA:2678

Neurofibromatosis type 6 (NF6), also referred as café-au-lait spots syndrome, is a cutaneous disorder characterized by the presence of several café-au-lait (CAL) macules without any other manifestations of neurofibromatosis or any other systemic disorder. 